\title{
Dermoscopy as an Important Tool for Differentiating Unilateral Nevoid Telangiectasia and Angioma Serpiginosum
}

\author{
Uriel Villela-Segura $^{1}$
}

1 Dermatology Department, Hospital Regional Licenciado Adolfo López Mateos ISSSTE, Mexico City, Mexico

Key words: unilateral nevoid telangiectasia, angioma serpiginosum, vascular skin tumors

Citation: Villela-Segura U. Dermoscopy as an important tool for differentiating unilateral nevoid telangiectasia and angioma serpiginosum. Dermatol Pract Concept. 2019;9(4):306-307. DOI: https://doi.org/10.5826/dpc.0904a14

Accepted: May 23, 2019; Published: October 31, 2019

Copyright: (92019 Villela-Segura. This is an open-access article distributed under the terms of the Creative Commons Attribution License, which permits unrestricted use, distribution, and reproduction in any medium, provided the original author and source are credited.

Funding: None.

Competing interests: The author has no conflicts of interest to disclose.

Authorship: The author takes responsibility for this publication.

Corresponding author: Uriel Villela-Segura, MD, Hospital Regional Licenciado Adolfo López Mateos ISSSTE, Av. Universidad 1321, Florida, BO 01030, Delegación Álvaro Obregón, Mexico City, Mexico. Email: uvise08@gmail.com

\section{Introduction}

Unilateral nevoid telangiectasia (UNT) is a benign cutaneous vascular disorder, first described by Blaschko in 1899 , characterized by clustered telangiectasias with a reticular appearance, blanching with diascopy, and often following a dermatomal pattern especially in $\mathrm{C} 3$ and $\mathrm{C} 4$ dermatomes, although there are reported cases without this distribution. The pathogenesis is linked mostly to estrogenic action to release nitric oxide causing capillary relaxation; this theory is supported by the predominance in female teenagers and patients with chronic liver disease presenting with this condition; however, the estrogenic role remains unclear because of the lack of receptors in skin and normal estrogen and progesterone levels in some patients with UNT [1].

\section{Case Presentation}

A 13-year-old female patient presented with a 16-month history of erythematous reticulated macules (Figure 1), sized from $5 \mathrm{~mm}$ to $30 \mathrm{~mm}$, affecting the right mammary

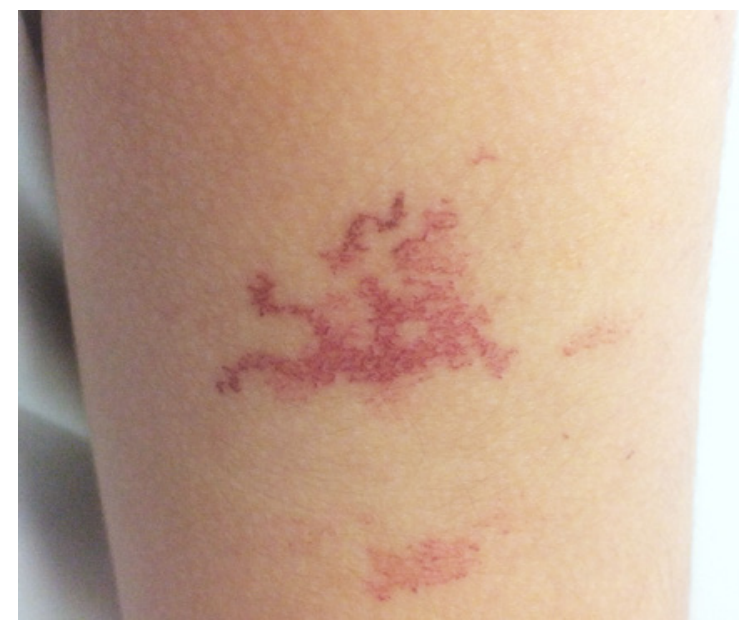

Figure 1. Red-violaceous reticulated macules. [Copyright: (C2019 Villela-Segura.]

region and posterior right arm, which was asymptomatic and appeared a few months after her menarche.

Dermoscopy showed red tortuous capillaries with a reticulated appearance (Figure 2). The lesion blanched completely with diascopy. Skin biopsy revealed a normal epidermis and 

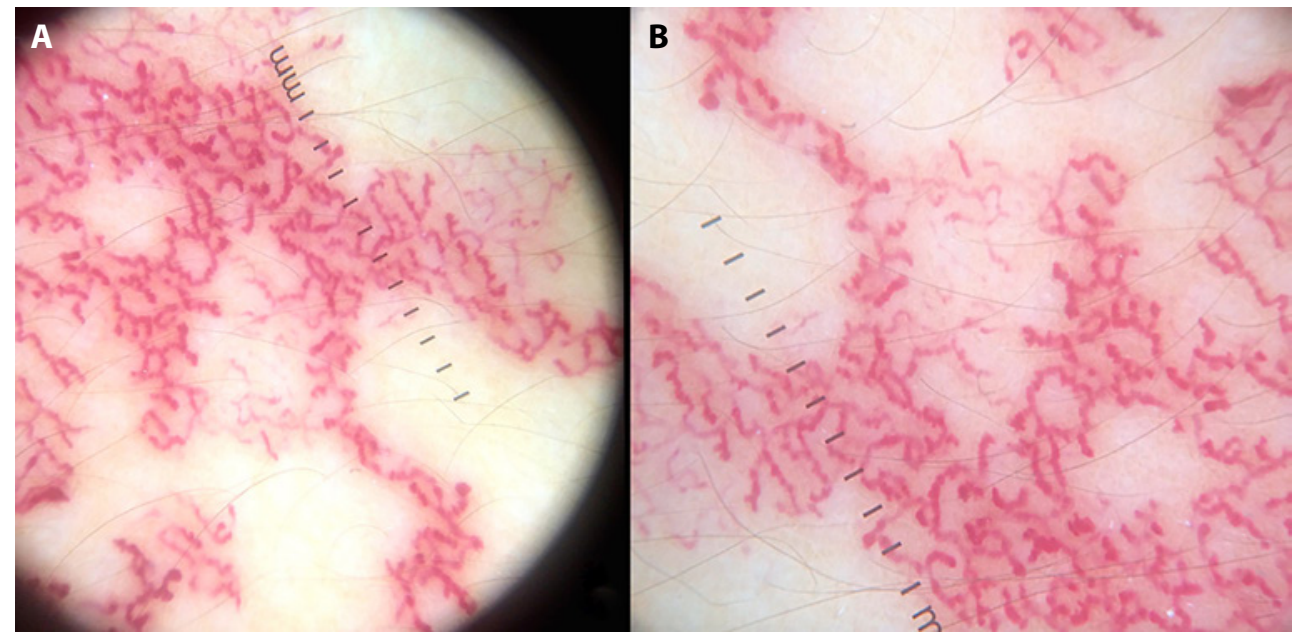

Figure 2. (A) Nonmelanocytic lesion with red tortuous capillaries on dermoscopy. (B) Reticular appearance. [Copyright: @2019 Villela-Segura.]

dilated capillaries composed of 1 endothelial layer in the papillary dermis (Figure 3). UNT was diagnosed and the patient received treatment with $\mathrm{Nd}$ :YAG laser, showing a good response.

The main clinical differential diagnosis is the angioma serpiginosum (AS), which is more common than UNT, appearing mostly in young female patients, and whose origin has been linked to estrogens as well as a mutation in the PORCN gene. Unlike UNT, this entity does not blanch with diascopy and in dermoscopy the presence of multiple red oval lagoons are characteristic. Histological findings are the same as in UNT [2].

Both conditions show excellent response with Nd:YAG laser. AS can be treated with a good outcome also with argon laser, $532 \mathrm{~nm}$ potassium titanyl phosphate laser, and intense pulsed light [1].

\section{Conclusions}

Dermoscopy is a useful tool to achieve the diagnosis of UNT, since red tortuous capillaries in a reticulated pattern are distinctive in this entity. These findings help us to differentiate this condition from the AS and to better select the most adequate aesthetic treatment.

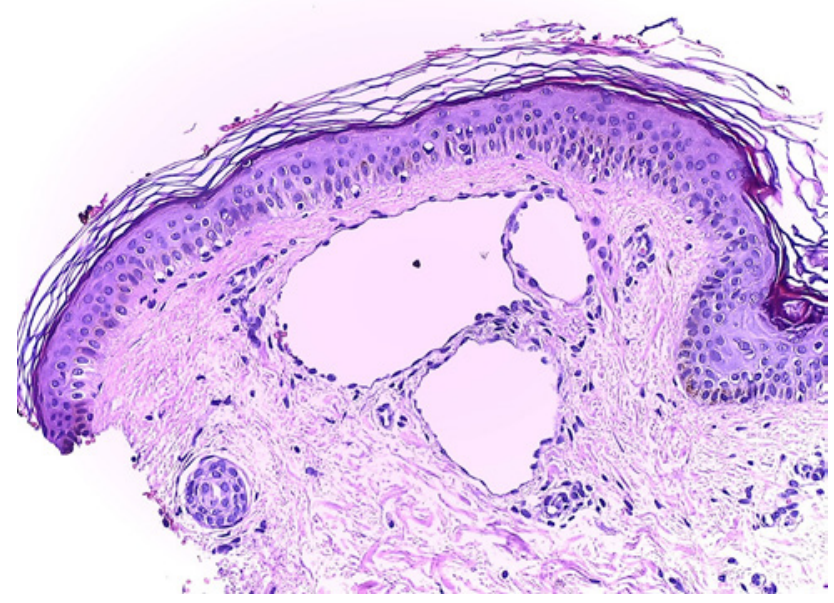

Figure 3. Dilated capillaries in dermis $(\mathrm{H} \& \mathrm{E}, \times 20)$. [Copyright: (C2019 Villela-Segura.]

\section{References}

1. Wenson SF, Jan F, Sepehr A. Unilateral nevoid telangiectasia syndrome: a case report and review of the literature. Dermatol Online J. 2011;17(5):2.

2. Ghanadan A, Kamyab-Hesari K, Moslehi H, Abasi A. Dermoscopy of angioma serpiginosum: a case report. Int J Dermatol. 2014;53(12):1505-1507. 